TUGAS FILSAFAT PANCASILA

STUDI KASUS MENGENAI PENGEBOMAN 3 GEREJA DI SURABAYA

Dr.Agustinus W.Dewantara,S.S.,M.Hum

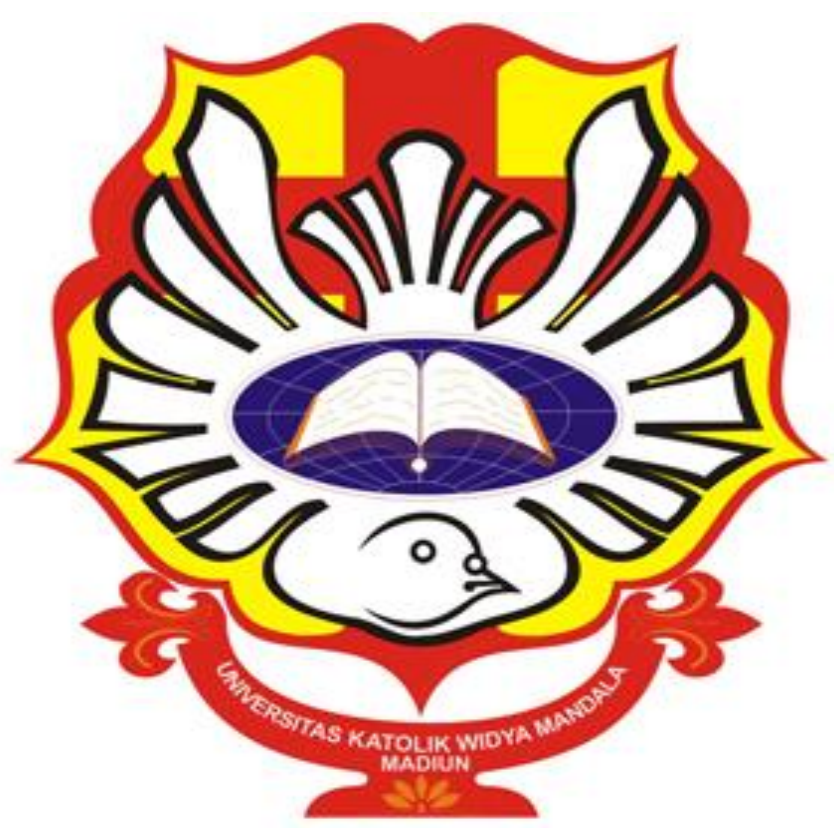

Disusun Oleh:

Agustina Elysa

(NIM: 3903019005)

FAKULTAS EKONOMI DAN BISNIS

JURUSAN MANAJEMEN

UNIVERSITAS KATOLIK WIDYA MANDALA SURABAYA KAMPUS MADIUN 


\begin{abstract}
ABSTRAK
Terorisme kerap kali terjadi di belahan dunia.Terorisme terjadi karena keinginan individu ataupun kelompok yang ingin mencapai maksud tertentu.Pemahaman yang tidak sesuai dengan hukum ini atau bertentangan dengan hukum akan mengakibatkan suatu dampak buruk bagi diri sendiri.

Tindakan terorisme ini kerap mengganggu kenyamanan masyarakat baik lokal atau di manapun.Masyarakat sering dihantui rasa takut dan tidak ingin melakukan aktifitas seperti teroris bila terdengar adanya teroris.

Seperti yang terjadi di kota Surabaya,terjadinya pengeboman di tiga buah bangunan Gereja.Hal ini mengakibatkan bangunan Gereja rusak dan memakan beberapa korban.Hal ini menjadi perhatian dunia mengenai kejadian ini.Amerika sendiri sebagai negara yang maju mengucapkan berbela sungkaya atas terjadinya pristiwa itu.Kejadian tersebut di kaitkan dengan ISIS yang terlibat untuk mengintimidasi masyarakat dan negara.
\end{abstract}

KATA KUNCI:(hati nurani,tanggung jawab,etika manusia) 


\section{STUDY KASUS}

\section{A.PENGEBOMAN TIGA GEREJA DI SURABAYA}

Pelaku bom bunuh diri di salah satu gereja di surabaya,Jawa Timur,Minggu 13/05,di duga seorang ibu yang membawa dua anaknya,kata seorang pejabat polisi setempat.

"Ibu dan dua anaknya yang berupaya masuk ruang kebaktian ini sempat dihalau oleh seorang sekuriti di pintu masuk GKI jalan Diponerogo,Surabaya,sebelum kemudian (ketiganya) meledakan diri di halaman gereja ," kata wakapolrestabes Surabaya,Ajun Komisaris Besar Benny Pramono.

Keterangan kepolisian ini berdasarkan kesaksian seorang satuan pengaman (satpam) gereja GKI di jalan Diponerogo,Surabaya.

Ibu dan dua anak tersebut berupaya masuk ke ruang kebaktian ini,setempat dihalau oleh seorang satpam di pintu masuk GKI Jalan Diponerogo Surabaya,sebelum mereka kemudian meledakan diri di halaman gereja.

"Sekuriti yang menghalaunya adalah salah satu korban yang terluka parah," ucap Benny kepada wartawan.

Menurut Benny,perempuan dewasa dan dua anak tersebut tewas seketika di lokasi kejadian.Belum diketahui hubungan antara perempuan dab dua bocah tersebut. Korban tewas terus bertambah

Sampai sekitar pukul 13.00 WIB,jumlah korban tewas akibat ledakan tiga gereja di Surabaya dan korban tewas terus bertambah menjadi sepulih orang dan melukai 40 orang lainnya,kata pejabat kepolisian.

Hasil identifikasi sementara kepolisian,sekitar pukul 13.00 WIB,menyebutkan 10 orang tewas dan 40 orang lainnya di larikan ke rumah sakit terdekat karena mengalami lukaluka.

Menurut polisi,bom pertama meledak sekitar pukul 07.30 WIB di Gereja Katolik Santa Maria Tak Bercela di Jalan Ngagel Madya Utara,Surabaya. 
Selang sekitar lima menit kemudian bom kedua meledak di gereja Pentakosta di jalan Arjuno,dan tidak lama kemudian bom meledak di gereja GKI di Jalan Diponerogo,kata polisi.

Empat orang tewas akibat ledakan bom di depan Gereja Santa Maria,dua orang tewas di gereja Pentakosta serta dua orang tewas lainnya di depan Gereja GKI,ungkap Frans Barung.

Polisi masih melakukan identifikasi terhadap korban yang meninggal dunia,dan jubir polda Jatim belum dapat memastikan apabila pelaku termasuk korban yang tewas dalam serangan bom ini.

Frans Barung mengatakan,kepolisisan akan menyampaikan perkembangan dari waktu ke waktu setiap jam.

'Saya melihat pelaku perempuan...'

Seorang saksi mata di Gereja Katolik Santa Maria,Lia mengatakan dirinya hendak menuju gereja Santa Maria saat bom meledak.

"Sudah dekat di lokasi,sekitar 100 meter,ada kerumunan massa,dan terdengar teriakan "Pulang!pulang!" saya sempat lihat prutulan (potongan) daging di sekitar lokasi.Takut,saya putar balik ke rumah," ungkapnya kepada wartawan BBC,Jarome Wirawan.

Sementara saksi lainnya,seperti dilaporkan Detik.com,mengku melihat seorang perempuan membawa dua anaknya yang dilihatnya "meledakan dirinya di depan halaman" Gereja Katolik Santa Maria di Jalan Ngagel Madya Utara Surabaya.

"Saya sempat melihat dua orang anak dan ibunya datang membawa dua tas," kata satpam,Antonius kepada wartawan di lokasi,Minggu 13/05.

Awalnya,menurutnya petugas menghalang perempuan dewasa di depan pagar halaman gereja,tetapi ibu itu tetap mencoba masuk."Tiba-tiba saja ibu itu memeluk petugas”,ungkapnya. “Tiba-tiba (bom) meledak,úngkap Antonius.

Dimintai konfirmasi atas kesaksian ini,Jubir Polda Jatim Kombes Frans Barung mengatakan pihaknya belum bisa memastikan karena polisi masih melakukan identifikasi terhadap delapan korban yang tewas. 
Pengamatan masalah teroris dari Universitas Indonesia,Stanislaus Riyanta mengatakan,dilihat dari model dan karakteristik serangan bom di tiga gereja Surabaya,ada indikasi kuat pelakunya adalah kelompok militan yang menamakan dirinya Negara Islam atau dulu disebut ISIS.

"Sasaran aksi teror di Indonesia hanya dua,tempat ibadah dan polisi.Ini gayanya ISIS dan harus diwaspadai," kata Stanislaus Riyanta kepada BBC Indonesia,minggu 13/05.

"Saya menduga ini tidak hanya berhenti disini.Tantangan berat bagi polri untuk menangani ini, tapi saya yakin polri mampu,’tambahnya.

Menurutnya,kasus kerusuhan di rumah tahanan teroris di rumah Mako Brimob,Kelapa Dua,Depok,menjadi alaram bagi kebngkitan sel tidur teroris di Indonesia.

"Dan sekarang mereka sudah bangkit," kata Stanislaus

\section{B. APA YANG DIMAKSUD DENGAN PENGEBOMAN}

Bom adalah alat alat yang menghasilkan ledakan yang mengeluarkan energi secara besar dalam rentang waktu singkat.Kata bom berasal dari bahasa Yunani (Bombos),sebuah istilah yang meniru suara ledakan 'bom' dalam bahasa tersebut.Alat peledak dalam militer juga banyak yang tidak disebut "bom".

\section{UNDANG-UNDANG TENTANG PENGEBOMAN}

Revisi Ungang-undang Nomor 15 Tahun 2003 tentang pemberantasan Tindak Pidana Teroris akhirnya disahkan menjadi Undang-undang.Pengesahan dilakukan dalam rapat paripurna di Kompleks Parlemen,Senayan,Jakarta,Jumat 25/05/2018.

Revisi ini sebenarnya sudah diajukan oleh pemerintah kepada DPR sejak Februari 2016.Namun,pembahasan antara DPR dan pemerintah berlangsung alot dan memakan waktu lama. Sejumlah aksi teror yang belakangan ini melanda tanah air pun menjadi pemicu agar UU ini segera disahkan.

Presiden Joko Widodo sempat mengancam akan menerbitkan pengaturan pemerintahan pengganti undang-undang apabila sampai bulan juni UU ini belum 
rampung.Sebab,revisi UU ini merupakan sebuah payung hukum yang penting bagi aparat untuk mencegah dan menindak kejahatan terorisme.

Namun akhirnya,panitia khusus RUU Antiterorisme di DPR serta kementrian dan lembaga terkait bisa menyelesaikan revisi UU sebelum tenggang waktu yang diberikan Joko Widodo.

\section{TINDAKAN MANUSIA}

Dari kasus pengeboman di Surabaya masuk ke dalam teoriTindakan manusia. Manusia bertindak dan harus bertindak."Harus bertindak" artinya bahwa tindakan itu harus memenuhi standar atau kriteria normatif tertentu.Bertindak adalah ciri khas setiap makhluk hidup.Bahwa manusia "harus" bertindak,itu melukiskan eksistensi manusia secara mendalam,karena tindakan manusia tidak hanya berkaitan dengan eksistensinya sebagai makhluk hidup,melainkan cuga mencetuskan nilai-nilai manusiawi.Magna terminologi memenuhi syarat moral atau etis tertentu.

Tindakan manusia adalah pencetusan dirinya.Maurice Blondel berkata bahwa tindakan manusia adalah representasi dirinya yang paling lengkap. Lebih lanjut Blondel menulis,"Tindakan adalah fakta yang paling menyeluruh sekaligus konstan dalam hidupku".Blondel hendak menegaskan bahwa tindakan adalah realitas yang paling menyakinkan perihal siapa dirinya.

Tindakan manusia tidak tunggal.Pernyataan ini bukan hendak menyatakan bahwa tindakan manusia itu jamak. Tindakan manusia tidak tunggal maksudnya:tindakan manusia itu kompleks,dinamis,dan kaya akan proses.Mengapa demikian?karena manusia sebagai subjek dari tindakannya adalah makhluk yang kompleks pula,berbeda dengan binatang.

Perbedaannya adalah:binatang bukan subjek dari tindakannya,sedangkan manusia secara tegas adalah subjek (tuan) atas tindakannya (meskipun pada kasus tertentu manusia kerap jatuh pada pengungkapan-pengungkapan seperti halnya binatang).prilaku binatang sebenarnya adalah "gerakan" yang amat didominasi oleh insting. Sementara tingkah laku manusia jelas tidak bisa melulu disempitkan pada gerakan fisik dan insting belaka.

Jadi,tindakan manusia adalah perwujutan dari perkembangan dari kemanusiaannya.Dalam kacamata berfikir inilah muncul aneka terminologi 
perkembangan,seperti:kedewasaan,kematangan,kemandirian,tanggung jawab,dan sejenisnya yang tidak bisa dibayangkan ada dalam dunia binatang.

\section{E. APA HUBUNGAN KASUS PENGEBOMAN DENGAN HATI NURANI?}

Hati nurani berarti hati manusia memiliki pengetahuan.Hatinurani ialah hati yang mengetahui.Sebenarnya proposisi "Hati yang mengetahui" sama sekali tidak tepat.Soal pengetahuan tak pernah merapak soal hati,melainkan soal akal budi (rasio).Dan sebab itu,jika dikatakan hati nurani mengetahui,maksudnya ialah hati kita memiliki semacam pertimbangan yang membimbing kehendak kita.

Pengetahuan hati seringkali lebih merupakan pengetahuan yang dicurahkan,diucapkan dalam hati kita.Hati nurani disebut juga "synderesis".Dalam bahasa inggris disebut "conscience" yang berkaitan langsung dengan kesadaran.Hatinurani menjadi seperti kapasitas/daya/kekuatan yang pertimbangan dan pAemeriksaannya mengatasi hukum,fenomena baik/buruk sebagaimana digagas oleh piblikkebanyakan,mengatasi larangan/perintah dalam peraturan-peraturan yang dimiliki dalam hidup manusia.

Karena hati nurani adalah "suara tuhan"aneka pertimbangan yang diberikan mengantar manusia kepada allah.Jadi hati nurani tidak sekedar berurusan dengan salah benar secara etis,melainkan langsung menunjukan kepada relasi manusia dengan allah dengan caracara yang tidak bisa di redukasi sekedar dalam agama-agama formal.jadi kasus pengeboman berkaitan dengan hati nurani manusia, karena setiaap manusia pasti memiliki hati nurani untuk melakukan segala sesuatu apa bila manusia tidak memiliki hati nurani berati manusia tidak bisa berfikir dengan baik tentang sesama manusia.

\section{F. MANUSIA YANG BERETIKA}

Secara umum dapat dikatakan dapat dijelaskan bahwa Etika adalah filsafat tentang tindakan manusia,tindakan tersebut memiliki nilai Etis bila dilakukan oleh manusia.Etika tersebut berurusan secara langsung dengan tindakan tingkah laku manusia.Tiangkah laku manusiawi bukanlah tingkah laku yang tidak ada artinya tetapi mengajarkan manusia berbagai nilai-nilai kebaikan.Penjelasan tentang etika seorang manusia adalah ilmu yang mengajarkan manusia tentang baik/buruk serta kewajiban moral.Kumpulan asas nilai yang berkenaan dengan akhlak,etika juga mengenai benar atau salah dianut suatu golongan atau masyarakat.Pengeboman yang terjadi di kota Surabaya Jawa Timur,semua orang pastinya mempunyai etika dalam kehidupan sehari-hari sama seperti pelaku pengeboman gereja di 
Surabaya tersebut.Disini pelaku bukan tidak mempunyai etika tetapi pelaku memiliki etika yang buruk tentunya.Etika buruk yang ia lakukan adalah pengeboman gereja tersebut,sedangkan etika yang baik dilakukan seorang manusia kepada sesama ialah menghargai,saling mengasihi,atau saling membantu satu sama lain.Karena mereka melakukan suatu tindakan yang membuat banyak korban terluka bahkan meninggal.Dapat kita ketahui bahwa manusia pasti mempunyai suatu tindakan dalam hidupnya dan setiap sebelum manusia tersebut bertindak pasti memiliki kata harus bertindak.Artinya tindakan tersebut harus memenuhi standar atau kriteria normatif tertentu.Manusia bertindak sesuai norma adalah ciri dari setiap makhul hidup,karena tindakat tidak hanya berkaitan dengan eksistensi sebagai makhluk hidup.

Semua yang diuraikan dalam kasus pengeboman di atas kita layaknya manusia yang memiliki etika yang baik ,kita juga harus bisa membedakan mana etika yang baik dan mana etika yang bururk.Manusia harus memiliki perbuatan moral artinya perbuatan yang ada dalam konteks kebebasan dan tanggung jawab yang akan kita lakukan di dalam kehidupan kita terhadap sesama.Manusia memiliki akhlak yang baik dalam kehidupan,dan memperluas pikiran yang baik untuk perkembanagan kemanusiaan.

\section{G. BAGAIMANA CARA MENGATASI AGAR TIDAK TERJADI PENGEBOMAN LAGI}

Sekjen pengurus besar (PBNU)Helmy Zaini mengatakan ada 3 hal yang dapat dilakukan guna mencari solusi persoalan terorisme ke depannya. Pertama,mendorong agar mendorong Undang-undang Terorisme segera disahkan.

Kedua,pemerintahan dapat memaksimalkan perangkat hukum yang sudah ada.Menurut Helmy,perangkat hukum yang sudah ada memungkinkan untuk digunakan senjata oleh aparat hukum dalam menindak para Teroris.

Ketiga,penertiban terhadap masjit-masjit yang terindikasi dikuasai oleh kelompok ekstrime perlu dilakukan.”Maka banyak langkah yang harus dilakukan”. Helmy menilai pristiwa bom tiga gereja Surabaya,kemarin menandakan kerja intelijen sangat lemah.Oleh karena itu,Helmy mengajak semua pihak mendukung pemerintah memberantas Terorisme.

Bahkan,lanjutnya toko lintas agama akan membuat posko kemanusiaan yang nantinya akan menghimbau data agar semuanya terjaga dengan baik.'Kami tokoh lintas agama berseru 
seluruh umat agar tidak terprovokasi.Kepata umat kristiani bahwa apa yang dilakukan di Surabaya bukan kami yang mengatas namakan Islam,"kata Helmy.

Mereka yang menebar teror,Helmy menambahkan,bukan termasuk islam.Karena semua agama tidak mengajarkan umatnya berbuat kekerasan. Helmy mengingatkan agar kewaspadaan ditingkatkan apalagi mausk di tahun politik pengelolaan keamanan harus sangat cermat. "Sehingga penumpang gelap,gerakan transnasional tidak memanfaatkan ini,"’tuturnya.

\section{G. PENCEGAHAN}

11 Cara yang bisa dilakukan untuk mencegah pertumbuhan bibit terorisme pada generasi muda:

\section{Perlunya menerapkan kurikulum anti-teror sejak dini.}

Usai aksi teror bom yang terjadi di Surabaya,kementrian Agama,kementrian pendidikan dan kebudayaan serta kementrian riset,Teknologi dan pendidikan Tinggi RI berencana segera menyusun kurikulum anti-teroe di Indonesia.Pendidikan antiteror akan dimasukan dalam muatan lokal di seluruh jenjang pendidikan di Indonesia.Upaya ini diharapkan dapat mengurangi aksi teror.

\section{Adanya khotbah dan ceramah agama yang positif.}

Hingga detik ini masih banyak anak bangsa yang terdoktrin untuk melakukan teror.Untuk mengatasinya maka diperlukan ceramah positif.Ceramah ini menjelaskan kepada semua jamaah bahwa teror di agama manapun dilarang dan membunuh orang adalah dosa besar.

\section{Marilah sebarkan indahnya keberagaman pada lingkungan di sekitar.}

Jika tak bisa dimulai dari hal yang besar,maka mulailah dari hal-hal yang kecil.Misalnya membangun atau membuat komunitas-komunitas kecil yang bertujuan untuk mengkampanyekan perdamaian dan indahnya keberagaman.

\section{Belajar mengenai perdamaian dan keberagaman.}

Mempersenjatai diri dengan pengetahuan keagamaan yang baik adalah cara terbaik untuk membentangi diri dari terorisme.Penting sekali untuk memperdalam pengetahuan mengenai keberagaman dan perdamaian.

\section{Menyaring segala informasi yang didapatkan.}

Sebagai generasi muda yang sadar teknologi,tentunya masing-masing dari kita wajib untuk menyaring informasi yang kita dapatkan.Karena terorisme juga tidak 
ketinggalan dalam memanfaatkan media dan teknologi untuk menyebarkan paham kekerasan dan radikal kepada anak muda.

\section{Sosialisasikan bahaya dan dampak terorisme.}

Dampak aksi teror memang sangat luar biasa.Oleh karena itu kita jangan sampai lupa untuk aktif sosialisasikan tentang hal ini.Masyarakat harus tau apa itu terorisme,bahaya dan dampaknya,pola mereka merekrut anggota,bentuk dan pola aksi mereka,dan masih banyak lagi.

7. Selalu aktif melapor jika ada aktivitas radikalisme dan terorisme di lingkungan sekitarmu.

Kamu juga harus menjadi orang yang sadar lingkungan sekitar.Marilah dengan berperan aktif dalam melaporkan dalam gejala-gejala sekecil apapun yang mengarah pada radikalisme atau terorisme.Jika ada sesuatu yang mencurigakan segera laporkan saja kepada pihak yang berwajib.

\section{Bekerja sama dengan pihak berwajib.}

Supaya langkah mendeteksi dan mencegah aksi terorisme bisa dilakukan dengan maksimal,maka perlu adanya jejaring antara pemda,polri,Sektor bisnis,media,LSM, dan masyarakat melalui Crisis center,seperti TMC,call center,dan sebagainya.

9. Meningkatkan kewaspadaan sehari-hari terhadap radikalisme.

Jangan mau dibohongi begitu saja dengan kata-kata yang mengandung unsur radikalisme.Tingkatkanlah kewaspadaan dalam pergaulan sehari-hari agar tidak mudah terpengaruh dengan paham atau ajakan terorisme.

10. Pemerintah juga harus lebih tegas dalam mencegah dan mnghukum tindakan terorisme.

Pemerintah juga harus melakukan langkah yang tegas dalam rangka menanggulangi terorisme.Hal ini dapat membuat para pelaku jera dan perpikir panjang sebelum merencanakan aksinya.

\section{1. bersama-sama membangun kesan bahwa kota kita aman dari terorisme.}

Dan yang paling penting adalah memberikan sugesti positif yang bisa dirasakn olah banyak masyarakat.Misalnya memberikan image atau kepercayaan kepada masyrakat bahwa kota kita aman,nyaman dan bersahabat. 


\section{DAFTAR PUSTAKA}

Dewantara, A. W. (2015). Pancasila Sebagai Pondasi Pendidikan Agama Di Indonesia. CIVIS, 5(1/Januari).

DEWANTARA, A. W. (2016). GOTONG-ROYONG MENURUT SOEKARNO DALAM PERSPEKTIF AKSIOLOGI MAX SCHELER, DAN SUMBANGANNYA BAGI NASIONALISME INDONESIA (Doctoral dissertation, Universitas Gadjah Mada).

Dewantara, A. W. (2017). Kerasulan Awam Di Bidang Politik (Sosial-Kemasyarakatan), Dan Relevansinya Bagi Multikulturalisme Indonesia. JPAK: Jurnal Pendidikan Agama Katolik, 18(9), 3-15.

Dewantara, A. W. (2013). Merefleksikan Hubungan antara Etika Aristotelian dan Bisnis dengan Studi Kasus Lumpur Lapindo.Arete, 2(1), 23-40.

Dewantara, A. W. (2018). Pendidikan Kewarganegaraan. Madiun: STKIP Widya Yuwana.

Dewantara, A. W. (2017). MULTIKULTURALISME INDONESIA (STUDI PERBANDINGAN ANTARA KONSEP MADANI NURCHOLISH MADJID DAN KONSEP CIVIL SOCIETY). JPAK: Jurnal Pendidikan Agama Katolik, 17(9), 15-25. 